\title{
BAGAIMANA KOMPTERENSI TUTOR DAN PELAKSANAAN TUTORIAL MEMPENGARUHI PRESTASI MAHASISWA: TELAAH DARI POKJAR GROBOGAN UPBJJ-UT SURAKARTA
}

\author{
Isman Suharto \\ Universitas Terbuka \\ Yulia Budiwati \\ Universitas Terbuka \\ Muhrom Ali Rozai \\ Tutor Universitas Terbuka \\ Kusbandi \\ Universitas Terbuka
}

\begin{abstract}
The research objective was to examine the effect of pedagogic competence, professional competence, personal competence, social competence and tutorial implementation on student achievement. The design / methodology of this research was carried out on I I 4 non Pendas students at Pokjar Grobogan UPBJJ UT Surakarta which were explored using a questionnaire. The analysis used is multiple regression analysis. The finding of a significant positive influence between pedagogic competence, professional competence, personal competence, social competence and tutorial implementation. The limitation of this research is the difficulty of controlling the respondents, namely that the questionnaire is filled out with other students (discussion) so that the results will risk bias the results.
\end{abstract}

Keywords: Pedagogic, Professional, Personal, Social

\begin{abstract}
ABSTRAK
Tujuan penelitian adalalah menguji pengaruh kompetensi pedagogik, kompetensi profesional, kompetensi keperibadian, kompetensi sosoal dan pelaksanaan tutorial pada prestasi mahasiswa. Desain/Metodologi penelitian ini dilakukan kepada II4 mahasiswa non pendas di Pokjar Grobogan UPBJJ UT Surakarta dieksplorasi menggunakan kuesioner. Analisis yang digunakan adalah analisis regresi berganda. Temuan adanya pengaruh positif signifikan antara kompetensi pedagogik, kompetensi profesional, kompetensi keperibadian, kompetensi sosoal dan pelaksanaan tutorial. Keterbatasan penelitian ini adalah sulitnya mengendalikan responden yaitu pengisian kuesioner diakukan bersama-sama mahasiswa lainya (diskusi) sehingga hasil akan berisiko menjadikan hasil menjadi bias.
\end{abstract}

Kata Kunci: Pedagogik, Profesional, Keperibadian, Sosoal

\section{PENDAHULUAN}

Prestasi belajar merupakan hasil yang dicapai peserta didik setelah melakukan kegiatan belajar. Karena kegiatan belajar merupakan proses, maka prestasi belajar adalah outputnya. Dengan demikian, baik tidaknya prestasi belajar mahasiswa, tentunya sangat ditentukan oleh baik tidaknya proses belajar yang dilakukannya (llyas, 2008)

Winkel (2009) mengemukakan bahwa prestasibelajar merupakan bukti keberhasilan yang telahdicapai oleh seseorang. Prestasi belajar meru-pakan hasil maksimum yang dicapai oleh se-seorang setelah melaksanakan usaha-usahabelajar. Gunarso (1985) mengemukakan bahwa prestasi belajar adalah usaha maksimal yangdicapai oleh seseorang setelah melaksanakanusahausaha belajar. Menurut Azwar (2006) prestasi belajar adalah performa maksim alseseorang dalam menguasai bahan-bahan ataumateri yang telah diajarkan atau telah dipelajari. Dari ketiga pendapat tersebut dapat ditarikinferetasi bahwa prestasi belajar sebagai buktikeberhasilan, hasil maksimal yang dicapai setelah belajar, dan performa maksimal dalam menguasaimateri yang dipelajari.
Prestasi belajar merupakan hasil kerja seseorang mahasiswa selama periode tertentu dibandingkan dengan berbagai kemungkinan. Mangkunegara (2000) menyatakan bahwa prestasi akademik adalah hasil kerja secara kualitas dan kuantitas yang dicapai oleh seseorang mahasiswa dalam melaksanakan tugasnya sesuai dengan tanggung jawab yang diberikan kepadanya.

Faktor yang mempengaruhi belajar yaitu faktor internal dan faktor eksternal. Faktor internal antara lain kondisi fisik, intelegensia, sikap, bakat, minat dan motivasi dalam diri mahasiswa. Sedangkan faktor eksternal yang mempengaruhi prestasi belajar antara lain lingkungan keluarga, lingkungan kampus dan lingkungan masyarakat. Slameto (2010). Penyelenggara pendidikan jarak jauh telah menyediakan berbagi sumber belajar untuk memudahkan mahasiswa dalam mengaksesnya. Sumber belajar utamanya adalah modul yang telah disediakan secara khusus untuk dapat dipelajari dengan mudah oleh mahasiswa. Selain menggunakan modul yang disediakan, mahasiswa juga dapat mengambil inisiatif untuk memanfaatkan perpustakaan, mengikuti tutorial tatap muka. Ketika 
dihadapkan dengan kesulitan dalam belajar, siswa dapat meminta bantuan tutorial (Hendrayana dkk, 20l4).

Undang-Undang Nomor 12 tahun 2012, kompetensi merupakan seperangkat pengetahuan, keterampilan, dan perilaku yang harus dimiliki, dihayati, dan dikuasai oleh seorang dosen dalam melaksanakan tugas keprofesionalannya. Kompetensi dosen meliputi empat kompetensi utama, yaitu kompetensi pedagogik, kompetensi kepribadiaan, kompetensi sosial, dan kompetensi profesional. Konsep kompetensi sudah mulai dibicarakan sejak lama dan pada saat itu timbul berbagai pengertian dan definisi tentang kompetensi. Hornby dan Thomas (Prihadi, 2004) mendefinisikan kompetensi sebagai pengetahuan, keterampilan dan kualitas-kualitas manajer atau leader yang efektif.

Kompetensi pedagogik penting karena menjadi penentu bagi keberhasilan proses belajar yang langsung menyentuh kemampuan pembelajaran Mulyasa (2007: 79). Penelitian ini dilakukan di Afrika Selatan, dengan hasil penelitian menemukan bahwa pengetahuan subjek, keterampilan mengajar, kehadiran dosen, dan sikap dosen memiliki pengaruh positif yang signifikan terhadap prestasi akademik siswa Muzenda (20l3). Peneltian ini juga dilakukan di di Nigeria, dengan 300 guru sebagai responden memperlihatkan bahwa guru yang efektif menghasilkan siswa yang berkinerja lebih baik Penelitian Akiri \& Ugborugbo (2009). Sebagian besar penelitian terdahulu menyatakan adanya hubungan signifikan dan positif antara kompetensi guru dan prestasi siswa, akan tetapi penelitin ini berbanding terbalik dengan penelitian di Ghana memperlihatkan yang menunjukan bahwa tingginya kualitas guru dalam hal kualifikasi akademik dan profesional ternyata tidak mempengaruhi hasil belajar siswa Bonney, Amoah, Micah, \& Lemaire (20I5). Selain itu penelitian di Kenya ini menunjukkan tidak ada hubungan yang signifikan antara kualifikasi guru dan prestasi akademik siswa (Kosgei, Mise, Odera, \& Ayugi, 20l3), penelitian di Kuwait menemukan bahwa tidak ada hubungan signifikan antara kualitas dosen dengan prestasi akademik mahasiswa (AlMutairi, 20II)

Dosen sangat mutlak memerlukan profesionalisme (Schwitzer, 2009). Hasil penelitian dari Husnan (2013) menghasilkan adanya pengaruh yang signifikan dan positif dari kompetensi profesional dosen terhadap kinerjanya. Senada dengan penelitian tersebut, hasil penelitian dari Susilowati $M$ dan Solikhan (2014) Profesionalisme akuntan pendidik : perspektif atau trigger Kualitas
Iulusan akuntansi di era Masyarakat Ekonomi Asean. Namun hal tersebut berbeda dengan penelitian yang sama terkait dengan Kompetensi profesional dosen dinilai cukup kompeten, walaupun tidak berpengaruh terhadap prestasi mahasiswa (Widyowati, 2014)

Proses belajar mengajar adalah suatu proses interaksi dosen dan mahasiswa yang bersifat mendidik dalam rangka mencapai tujuan pendidikan. Dosen yang mampu menunjukan sifat atau kepribadian sebagai pengajar yang meliputi fleksibilitas kognitif dosen, keterbukaan psikologis dosen dan sifat-sifat pribadi dosen (ChamorroPremuzic et al., 2007). Perilaku belajar yang baik akan membuat seorang mahasiswa lebih memahami materi kuliah, sehingga bisa menghasilkan prestasi akademik yang baik, perilaku belajar merupakan kebiasaan yang di lakukan oleh mahasiswa dalam proses pembelajarannya seperti penggunaan waktu belajar, kelengkapan materi dan cara dalam menangkap dan memahami suatu materi (Widatik, 2016)

Dosen harus mampu menciptakan situasi yang dapat menunjang perkembangan belajar mahasiswa. Semua ini tidak terlepas dari bagaimana seorang dosen menampilkan kepribadiannya dalam proses belajar mengajar, sehingga muncul pendapat bahwa dosen adalah motivator bagi peserta didik/mahasiswanya (Bathmaker, 2005; Henderson \& Braday, 2008; Maxwell, 2010)

Kompetensi sosial merupakan wilayah faktor yang secara psikologis mempengaruhi keberhasilan dalam belajar. Sebagaimana dikatakan oleh Allen dkk (2009) kompetensi sosial merupakan prediktor bagi penyesuaian diri yang sehat sebagai bekal yang penting untuk mencapai keberhasilan secara sosial maupun akademis serta merupakan prediktor kesehatan mental dan penyesuaian diri dalam sepanjang rentang kehidupan. penelitian Irianto (2015) penilaian mahasiwa belum memuaskan terutama yang berkaitan dengan kemampuan dosen mengenal mahasiswa dengan baik demikian pula pergaulan dosen dengan mahasiswa. Kompetensi sosial memiliki pengaruh yang signifikan dalam meningkatkan kinerja belajar Hakim (20I5)

Penelitian ini dilakukan di Afrika Selatan, dengan hasil penelitian menemukan bahwa pengetahuan subjek, keterampilan mengajar, kehadiran dosen, dan sikap dosen memiliki pengaruh positif yang signifikan terhadap prestasi akademik siswa Muzenda (20/3). Peneltian ini juga dilakukan di di Nigeria, dengan 300 guru sebagai responden memperlihatkan bahwa guru yang efektif 
menghasilkan siswa yang berkinerja lebih baik Penelitian Akiri \& Ugborugbo (2009).

Sebagian besar penelitian terdahulu menyatakan adanya hubungan signifikan dan positif antara kompetensi guru dan prestasi siswa, akan tetapi penelitin ini berbanding terbalik dengan penelitian di Ghana memperlihatkan yang menunjukan bahwa tingginya kualitas guru dalam hal kualifikasi akademik dan profesional ternyata tidak mempengaruhi hasil belajar siswa Bonney, Amoah, Micah, \& Lemaire (20I5). Selain itu penelitian di Kenya ini menunjukkan tidak ada hubungan yang signifikan antara kualifikasi guru dan prestasi akademik siswa (Kosgei, Mise, Odera, \& Ayugi, 20I3

Fasilitas yang baik akan membuat seorang mahasiswa akan merasakan kepuasan yang lebih baik. Prestasi mahasiswa tidak hanya didukung oleh faktor intelektualnya saja tetapi juga ditentukan ketersediaan fasilitas dalam kampus. Salah satu faktor yang mempengaruhi prestasi mahasiswa adalah fasilitas sebagai pengimbang dari kualitas pelayanan. Kedua hal ini harus tersus dikelola dengan baik, sehingga akan membantu perguruan tinggi untuk mencapai tujuan yaitu pelayanan prima bagi customer di universitas yaitu mahasiswa dan dosen (Frisdiantara dan Graha, 2013). Fasilitas perkuliahan dianggap cukup memadai dan tidak berpengaruh terhadap prestasi mahasiswa (Widyowati, 20l4).

UPJJ-UT Surakarta membuka kelas di Kota Purwodadi dean dikelan dengan Pokjar Grobogan Pokjar Grobogan memiliki mahasiswa yang banyak dan memiliki mahasiswa dengan bebrapa fakultas, letak pokjar yang jauh dari Kanor UPBJJ-UT Surakarta, dilihat dari aspek pengawaan yang tidak bisa mengawasi proses tuorial setiap pekanya. Selian itu tempat pembelajaran yang menggunakan fasilitas fihak ketiga yaitu SMK Pancasila, ini berkaitan dengan fasilitas pembelajaran yang di terima oleh peserta didik, sehingga peniliannya akan lebih obyektif. Sehingga dari faktr itu perlu adanya evaluasi proses pembelajaran sehingga mahasiswa memeproleh pelayanan yang baik dan hasil belajar yang baik juga

Dari penjelasan diatas, penelitian ini akan berfokus bagaimana langkahlangkah yang harus dilakukan untuk penyelesain masalah kinerja dan kompetensi tutor, penyelenggaraaan tutorial. Bagaimana meningkatkan kinerja dan kompetensi tutor, penyelenggaraaan tutorial bagi mahasiwa sehingga diharapkan prestasi mahasiswa dapat dicapai dnegan maksimal. Sehingga dari permasalahan tersebut sehingga hipotesa penelitian berupa:
$H_{1}$ : terdapat pengeruh positif kompetensi pedagogik tutor terhadap prestasi belajar mahasiswa Non Pendas di UPBJJ-UT Surakarta.

$\mathrm{H}_{2}$ : terdapat pengeruh positif kompetensi profesional tutor terhadap prestasi belajar mahasiswa Non Pendas di UPBJJ-UT Surakarta.

$\mathrm{H}_{3}$ : terdapat pengeruh positif kompetensi keperibadian tutor terhadap prestasi belajar mahasiswa Non Pendas di UPBJJ-UT Surakarta.

$\mathrm{H}_{4}$ : terdapat pengeruh positif kompetensi sosial tutor terhadap prestasi belajar mahasiswa Non Pendas di UPBJJ-UT Surakarta.

$\mathrm{H}_{5}$ : terdapat pengeruh positif proses pelaksanaan tutorial terhadap prestasi belajar mahasiswa Non Pendas di UPBJJ-UT Surakarta.

\section{METODE PENELITIAN}

Objek dalam penelitian direncanakan adalah mahasiswa Non Pendas pada UPBJJUT Surakarta Pokjar Grobogan. Pokjar Grobogan menjadi pertimbangan peneliti untuk menetapkan setting penelitian tersebut. Penelitian ini dipilih diwilayah Pokjar Grobogan, disebabkan faktor pertama, Pokjar Grobogan memiliki mahasiswa jumlah yang banyak dan memiliki bebrapa fakultas. kedua Letak dan tempat proses Tutorial Tatap Muka yang jauh dari Kanor UPBJJ-UT Surakarta, ini menjadi faktor pertimangan tim peneliti karena aspek pengawaan, Tim dari UPBJJ-UT Surakarta yang tidak bisa mengawasi proses tuorial setiap pekanya. ketiga tempat pembelajaran yang menggunakan fasilitas fihak ketiga, ini terkait dengan fasilitas pembelajaran yang di terima oleh peserta didik, sehingga peniliannya akan lebih obyektif.

Sumber data dalam penelitian ini adalah pertama, informan atau nara sumber, yang terdiri dari pengelola pembelajaran dan tutor. Kedua, mahasiswa non pendas UPJJ-UT Surakarta Pokjar Grobogan. Ketiga, Dokumen-dokumen yang tersimpan pada UPBJJ-UT Surakarta berupa Indeks Prestasi Mahasiswa.

Peneliti melakukan kegiatan secara intensif dengan maksud dapat mengamati dan menelusur berbagai ragam aktivitas Penyelengara, Tutor dan Mahasiswa. Kegiatan pengumpulan data dilakukan dengan dua cara. Pengumpulan Data Primer dilakukan melalui: survey research dengan menggunakan kuisioner, Kesioner yang harus diisi oleh mahasiswa non pendas yang terdiri dari Kompetensi Pedagogik, Kompetensi, Profesional, Kompetensi Kepribadian, 
Kompetensi Sosial dan Penilian Proses Perkuliahan yang menitik bertakan pada fasilitas dan pelayanan terhadap mahasiswa. Kuesioner yaitu suatu daftar pertanyaan tertulis yang digunakan untuk memperoleh informasi dari responden dalam arti laporan tentang pribadinya atau hal- hal yang ia ketahui (Arikunto, 2002).

Peneliti mengabil sempling dengan menggunakan teknik nonprobability sampling dengan menggunakan teknik Purposive sampling yaitu pengambilan sampling dengan pertimbangan tertentu (Sekaran, 2013), dengan kriteria pemilihan sampel pada penilitian ini adalah I) mahasiswa minimal semeter 2 (dua), ini dipilih karena mahasiwa sudah mengikuti kegiatan tutoral selama 2 (dua) kali sehingga bisa menilai pelaksanaan tutorial dan bisa menilai proses tutorial yang masing-maisng tutor pengampu mata kuliah dan fasilitas pelayanan yang diterima mahasiswa ; 2) bukan mahasiswa transfer atau bersumber dari D3; 3) Bukan meruakan mahasiswa Jurusan PGSD dan jurusan PAUD.

Model analisis yang digunakan untuk menganalisis pengaruh variabel independen terhadap variabel dependen adalah regeresi linier berganda. Model ini dipilih disebabkan penelitian ini dirancang untuk meneliti variabel-variabel bebas yang berpengaruh terhadap variabel terkait. Model yang digunakan dalam penelitian ini disajikan dalam persamaan sebagai berikut:

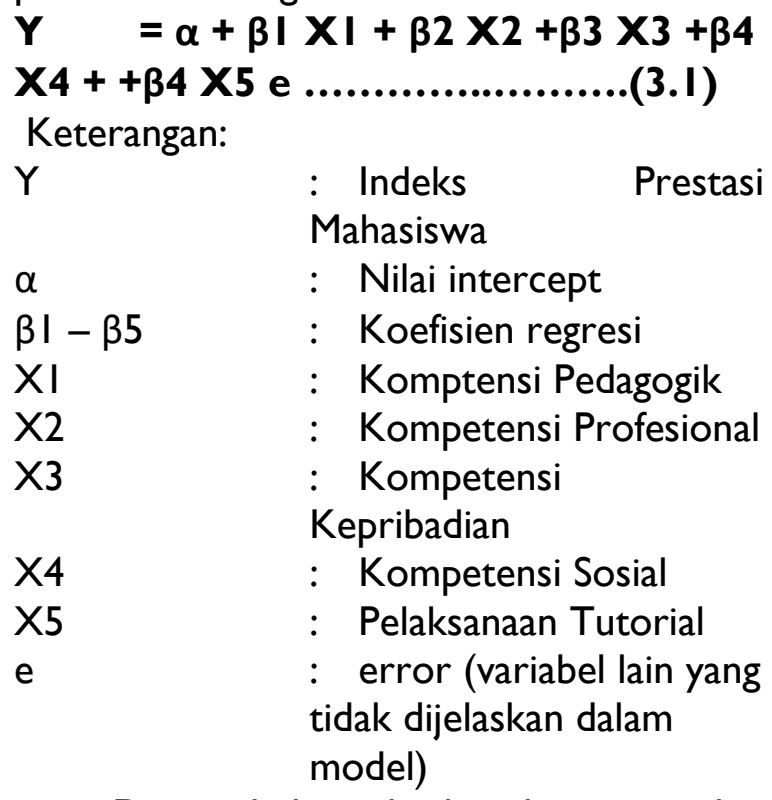

Data sebelum diujikan ke responden perlu dilakukan uji coba intrumen fungsinya untuk mengetahui validitas dan reliabilitas instrument. Analisis data dalam penelitian ini yaitu analisis data statistik dengan melakukan uji regresi. Sebelum dianalisis dengan uji regresi maka dilakukan uji hipotesis perlu adanya uji prasyarat uji asumsi klasik yang berupa uji normalitas dan uji heterokedaktisitas. Uji hepotesis penelitian ini yaitu uji t untuk mengetahui hubungan secara parsial variabel bebas terhadap variabel terika., uji $f$ untuk mengetahui hubungan secara simultan antar variabel bebas terhadap variabel terikat.

\section{HASIL PENELITIAN DAN PEMBAHASAN}

\section{Data Penelitian}

Data penelitian yang digunakan dalam penelitian ini merupakan data primer yang diperoleh dengan menggunakan daftar pertanyaan (kuesioner) yang telah disebarkan kepada mahasiswa non pendas Pokjar Grobogan UPJJ UT Surakarta. Kuesioner yang kembali dari proses penyebaran adalah I 17 kuesioner dan kuesioner yang digunakan dalam penelitian ini sebanyak II4 kuesioner.

\section{Uji Instrumen Data dan Uji}

\section{Normalitas Data}

Berdasarkan proses pengujian validitas dan reliabilitas, maka diperoleh semua valid dan reliable Tabel I dan Tabel 2

Tabel I Hasil Uji Validitas

\begin{tabular}{cccc}
\hline No Soal & $r$ hitung & $r$ tabel & Keterangan \\
\hline Item I & $.945^{* *}$ & 0.3809 & Valid \\
Item2 & $.803^{* *}$ & 0.3809 & Valid \\
Item3 & $.604^{*}$ & 0.3809 & Valid \\
Item4 & $.760^{* *}$ & 0.3809 & Valid \\
Item5 & $.517^{*}$ & 0.3809 & Valid \\
Item6 & $.758^{* *}$ & 0.3809 & Valid \\
Item7 & $.748^{* *}$ & 0.3809 & Valid \\
Item8 & $.862^{* *}$ & 0.3809 & Valid \\
Item9 & $.609^{* *}$ & 0.3809 & Valid \\
Item I0 & $.794^{* *}$ & 0.3809 & Valid \\
Item II & $.767^{* *}$ & 0.3809 & Valid \\
Item I2 & $.935^{* *}$ & 0.3809 & Valid \\
Item I3 & $.725^{* *}$ & 0.3809 & Valid \\
Item I4 & $.896^{* *}$ & 0.3809 & Valid \\
Item I5 & $.745^{* *}$ & 0.3809 & Valid \\
Item I6 & $.67 I^{* *}$ & 0.3809 & Valid \\
Item I7 & $.935^{* *}$ & 0.3809 & Valid \\
Item I8 & $.502^{*}$ & 0.3809 & Valid \\
Item I9 & $.649^{* *}$ & 0.3809 & Valid \\
Item20 & $.673^{* *}$ & 0.3809 & Valid \\
Item2I & $.804^{* *}$ & 0.3809 & Valid \\
Item22 & $.84 I^{* *}$ & 0.3809 & Valid \\
Item23 & $.862^{* *}$ & 0.3809 & Valid \\
Item24 & $.83 I^{* *}$ & 0.3809 & Valid \\
Item25 & $.945^{* *}$ & 0.3809 & Valid \\
\hline I* 25 & .5 &
\end{tabular}

**. Correlation is significant at the 0.0 I level (2-tailed).

*. Correlation is significant at the 0.05 level (2-tailed).

Sumber: Data Primer diolah, 2020

Tabel 2 Hasil Uji Realibilitas Variabel Penelitian

\begin{tabular}{cc}
\hline Cronbach's Alpha & N of Items \\
\hline .965 & 25 \\
\hline
\end{tabular}

Sumber: Data Primer diolah, 20

Uji asumsi klasik penelitian menggunakan uji normalitas, uji multikolinieritas, dan uji 
heteroskedastisitas. Hasil pengujian data dalam penelitian ini lolos dari uji asumsi klasik yang meliputi normalitas, multikolinieritas, dan heteroskedastisitas. Secara lengkap hasil pengujian asumsi klasik dapat dilihat pada Tabel 3, Tabel 4 dan Tabel 5

\section{Tabel 3 Hasil Uji Normalitas}

\begin{tabular}{llr}
\hline & & $\begin{array}{c}\text { Unstandardize } \\
\text { d Residual }\end{array}$ \\
\hline $\mathrm{N}$ & $\mathrm{II4}$ \\
Normal & Mean & $\begin{array}{r}0 \mathrm{E}-7 \\
\text { Parameters }\end{array}$ \\
$\mathrm{b}$ & Std. & .61429139 \\
& Deviatio & \\
Most & $\mathrm{n}$ & \\
Extreme & Absolute & .085 \\
Differences & Positive & .047 \\
Kolmogorov-Smirnov Z & -.085 \\
Asymp. Sig. (2-tailed) & .902 \\
\hline a. Test distribution is Normal. \\
b. Calculated from data.
\end{tabular}

Sumber : Data primer diolah, 2020

\section{Tabel 4 Hasil Uji Mulikolinearitas}

\begin{tabular}{cccl}
\hline \multirow{2}{*}{ Model } & \multicolumn{2}{c}{ Collinearity } & \\
\cline { 2 - 3 } & $\begin{array}{c}\text { Statistics } \\
\text { Toler }\end{array}$ & Keputusa \\
ance & VIF & \\
\hline $\begin{array}{l}\text { (Constant) } \\
\text { Pedagogik }\end{array}$ & .329 & 3.042 & $\begin{array}{l}\text { Tidak ada } \\
\text { multikolin } \\
\text { earitas }\end{array}$ \\
Profesional & .465 & 2.150 & $\begin{array}{l}\text { Tidak ada } \\
\text { multikolin } \\
\text { earitas }\end{array}$ \\
Keperibadia & .397 & 2.518 & $\begin{array}{l}\text { Tidak ada } \\
\text { multikolin } \\
\text { earitas }\end{array}$ \\
Sosoal & .439 & 2.280 & $\begin{array}{l}\text { Tidak ada } \\
\text { multikolin } \\
\text { earitas }\end{array}$ \\
Pelaksanaan & .343 & 2.917 & $\begin{array}{l}\text { Tidak ada } \\
\text { multikolin } \\
\text { earitas }\end{array}$ \\
\hline Tutorial & & &
\end{tabular}

a. Dependent Variable: IPK

Sumber: Data primer diolah, 2020

Tabel 5 Hasil Uji Heteroskedastisitas

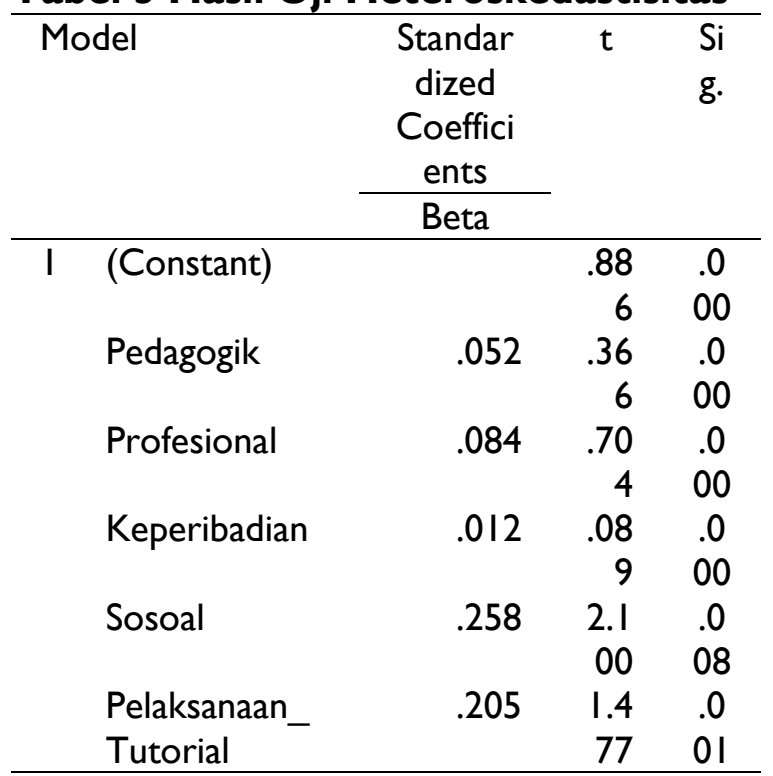

a. Dependent Variable: IPK

Sumber: Data primer diolah, 2020

\section{Analisis Regresi Berganda}

Hasil pengujian atas model regresi berganda untuk menguji hipotesis menggunakan SPSS 25 dengan menggunakan model persamaan yang telah disusun. Signifikansi level yang digunakan untuk menguji hipotesis adalah $1 \%$ dan 5\%. Hasil regresi disajikan pada Tabel 6

Tabel 6. Hasil Regresi

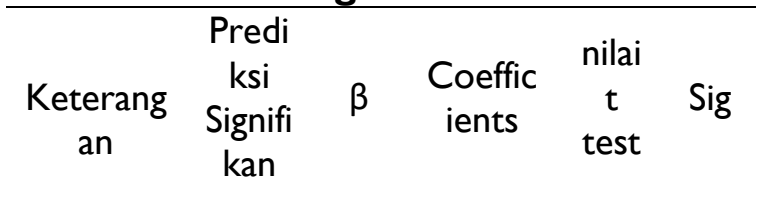

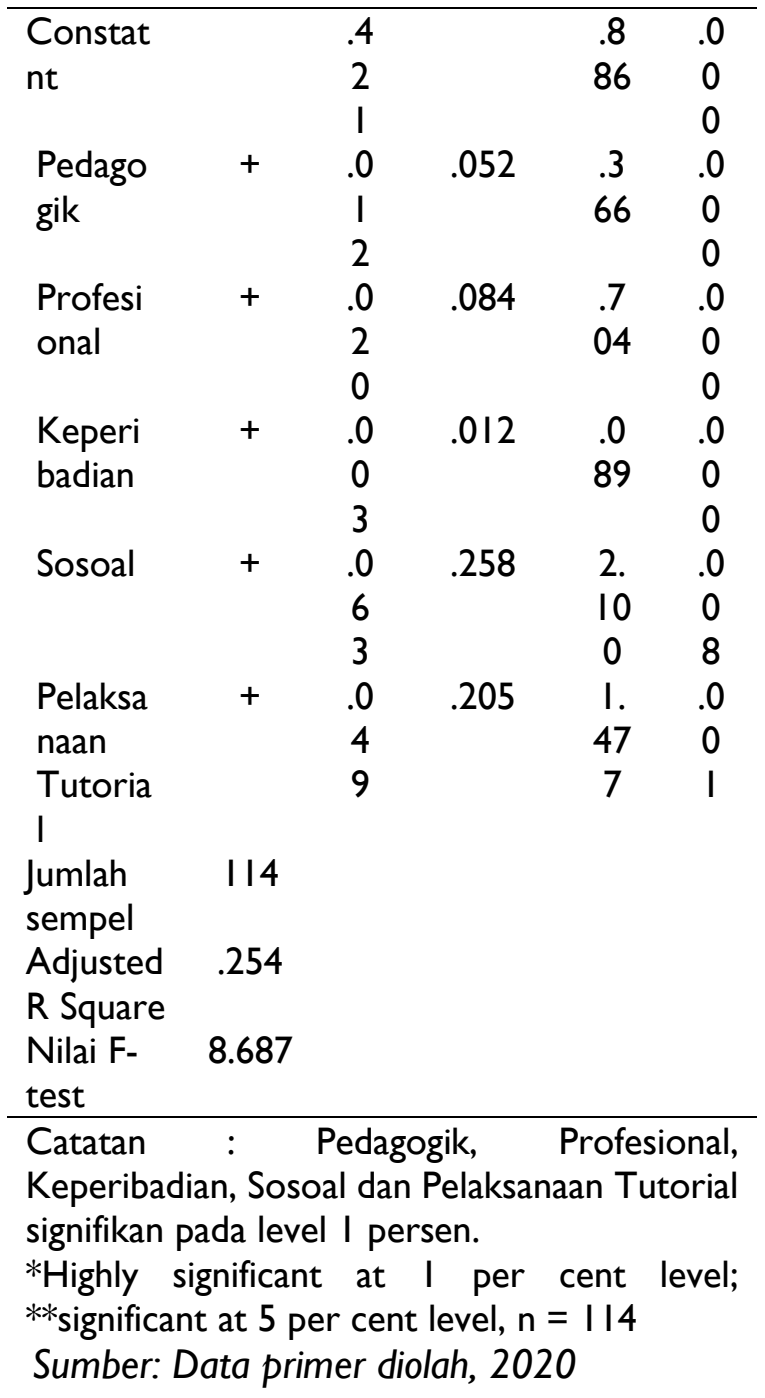

Berdasarkan Tabel 5, nilai-nilai tersebut terlihat bahwa Pedagogik (XI), Profesional (X2), Keperibadian (X3), berpengaruh signifikan terhadap prestasi mahasiswa pada tingkat signifikansi t lebih kecil dari $\alpha=0,0$ I yakni $t(X I)=0,000$. Sosoal $(X 4)$ dan Pelaksanaan Tutorial (X5) juga berpengaruh terhadap prestasi mahasiswa pada tingkat signifikansi t lebih besar dari $\alpha=0,01$ yakni $t$ $(X 2)=0,008$ dan $000 \mathrm{I}$. Hasil pengujian ini juga mendukung hipotesis $\mathrm{HI}$ dan, $\mathrm{H} 2$

Besarnya nilai adjusted R2 dengan menggunakan persamaan regresi adalah 0,254 pada Tabel 5. Nilai ini menunjukkan 
bahwa $25,40 \%$ variasi Kopetensi dan proses pelaksanaan tutorial dapat dijelaskan oleh variasi sedangkan sisanya sebesar $74,60 \%$ dipengaruhi oleh faktor-faktor lain yang tidak masuk ke dalam model penelitian. Selain itu berdasarkan nilai uji $\mathrm{F}$ pada tabel 5 untuk uji simultan diperoleh sebesar 8,687 dengan tingkat signifikansi sebesar 0,000 . Niali signifikansi uji $F$ lebih kecil dari 0,05 maka dapat disimpulkan bahwa model regresi yang digunakan untuk mengetahui pengaruh Pedagogik, Profesional, Keperibadian, Sosoal dan Pelaksanaan Tutorial pada prestasi mahasiswa adalah layak (fit).

\section{Pembahasan}

Penelitian ini menguji Pedagogik, Profesional, Keperibadian, Sosoal dan Pelaksanaan Tutorial pada prestasi mahasiswa. Berdasarkan Tabel 5 persamaan regresi dapat ditulis seperti dibawah ini.

\section{Prestasi $=0.421+0.012$ Komptensi Pedagogik +0.020 Kompetensi Profesional + $0.003 \quad$ Kompetensi Kepribadian +0.063 Kompetensi Sosial + 0.049 Pelaksanaan Tutorial}

Secara keseluruhan, hasil pengujian hipotesis dengan menggunakan regresi berganda dapat dilihat pada Tabel 6

Tabel 6. Ringkasan Hasil Pengujian Hipotesis

\begin{tabular}{|c|c|c|}
\hline Hipotesis & Hipotesis & Hasil \\
\hline $\mathrm{H}_{1}$ & $\begin{array}{l}\text { Kompetensi Pedagogik } \\
\text { akan berpengaruh } \\
\text { positif terhadap } \\
\text { prestasi mahasiswa. }\end{array}$ & Diterima \\
\hline $\mathrm{H}_{2}$ & $\begin{array}{lr}\text { Kompetensi } & \\
\text { Profesional } & \text { akan } \\
\text { berpengaruh } & \text { positif } \\
\text { terhadap } & \text { prestasi } \\
\text { mahasiswa. } & \\
\end{array}$ & Diterima \\
\hline $\mathrm{H}_{3}$ & $\begin{array}{lr}\text { Kompetensi } & \\
\text { Keperibadian } & \text { akan } \\
\text { berpengaruh } & \text { positif } \\
\text { terhadap } & \text { prestasi } \\
\text { mahasiswa. } & \\
\end{array}$ & Diterima \\
\hline $\mathrm{H}_{4}$ & $\begin{array}{l}\text { Kompetensi Sosial } \\
\text { akan berpengaruh } \\
\text { positif terhadap } \\
\text { prestasi mahasiswa. }\end{array}$ & Diterima \\
\hline $\mathrm{H}_{5}$ & $\begin{array}{l}\text { Kompetensi } \\
\text { Pelaksanaan tutorial } \\
\text { akan berpengaruh } \\
\text { positif terhadap } \\
\text { prestasi mahasiswa. }\end{array}$ & Diterima \\
\hline
\end{tabular}

\section{Pengaruh kompetensi Pedagogik} terhadap prestasi mahasiswa.

Pengujian hipotesis pertama $(\mathrm{HI})$ memiliki nilai $\beta I=0.012$ dengan tingkat signifikansi sebesar 0,000 (sig<0,05), sehingga $\mathrm{HI}$ diterima. Jadi variabel Kompetensi Pedagogik berpengaruh positif pada prestasi mahasiswa. Hasil penelitian ini sejalan dengan penelitian ini dilakukan di Afrika Selatan, dengan hasil penelitian menemukan bahwa pengetahuan subjek, keterampilan mengajar, kehadiran dosen, dan sikap dosen memiliki pengaruh positif yang signifikan terhadap prestasi akademik siswa Muzenda (20l3). Peneltian ini juga dilakukan di di Nigeria, dengan 300 guru sebagai responden memperlihatkan bahwa guru yang efektif menghasilkan siswa yang berkinerja lebih baik Penelitian Akiri \& Ugborugbo (2009) Dengan hasil tersebut berarti semakin tinggi kompetensi pedagogik maka akan semakin mempengaruhi prestasi mahasiswa. Dapat disimpulkan adanya hubungan antara kompetensi pedagogik dengan prestasi mahasiswa, bahwa seorang tutor memiliki kompetensi pedagogik tinggi maka kemungkinan prestasi mahasiswa juga meningkat.

\section{Pengaruh kompetensi Profesional terhadap prestasi mahasiswa.}

Pengujian hipotesis pertama $(\mathrm{H} 2)$ memiliki nilai $\beta 2=0.020$ dengan tingkat signifikansi sebesar 0,000 (sig<0,05), sehingga H3 diterima. Jadi variabel Kompetensi Profesioanl berpengaruh positif pada prestasi mahasiswa. Hasil penelitian ini sejalan denga penelitian dari Husnan (2013) menghasilkan adanya pengaruh yang signifikan dan positif dari kompetensi profesional dosen terhadap kinerjanya. Senada dengan penelitian tersebut, hasil penelitian dari Susilowati M dan Solikhan (2014) Profesionalisme akuntan pendidik : perspektif atau trigger Kualitas lulusan akuntansi di era Masyarakat Ekonomi Asean. Dengan hasil tersebut berarti semakin tinggi kompetensi profesional maka akan semakin mempengaruhi prestasi mahasiswa. Dapat disimpulkan adanya hubungan antara kompetensi profesional dengan prestasi mahasiswa, bahwa seorang tutor memiliki kompetensi profesional tinggi maka kemungkinan prestasi mahasiswa juga meningkat.

\section{Pengaruh kompetensi Keperibadian terhadap prestasi mahasiswa.}

Pengujian hipotesis pertama $(\mathrm{H} 3)$ memiliki nilai $\beta 3=0.003$ dengan tingkat signifikansi sebesar 0,000 (sig<0,05), sehingga H3 diterima. Jadi variabel Kompetensi Keperibadian berpengaruh positif pada prestasi mahasiswa. Perilaku belajar yang baik akan membuat seorang mahasiswa lebih memahami materi kuliah, sehingga bisa menghasilkan prestasi akademik yang baik, perilaku belajar merupakan kebiasaan yang di lakukan oleh mahasiswa dalam proses pembelajarannya seperti penggunaan waktu belajar, kelengkapan materi dan cara dalam 
menangkap dan memahami suatu materi (Widatik, 2016) hasil penelitin in isejalan dengan penelitian diatas. Dengan hasil tersebut berarti semakin tinggi kompetensi keperibadian maka akan semakin mempengaruhi prestasi mahasiswa. Dapat disimpulkan adanya hubungan antara kompetensi keperibadian dengan prestasi mahasiswa, bahwa seorang tutor memiliki kompetensi keperibadian tinggi maka kemungkinan prestasi mahasiswa juga meningkat.

\section{Pengaruh kompetensi Sosial terhadap prestasi mahasiswa.}

Pengujian hipotesis pertama $(\mathrm{H} 4)$ memiliki nilai $\beta 4=0.063$ dengan tingkat signifikansi sebesar 0,008 (sig<0,05), sehingga H4 diterima. Jadi variabel Kompetensi Sosial berpengaruh positif pada prestasi mahasiswa. Penelitian ini sejalan dnegan penelitian penelitian Irianto (2015) penilaian mahasiwa belum memuaskan terutama yang berkaitan dengan kemampuan dosen mengenal mahasiswa dengan baik demikian pula pergaulan dosen dengan mahasiswa. Dengan hasil ini berarti semakin tinggi kompetensi sosial maka akan semakin mempengaruhi prestasi mahasiswa. Dapat disimpulkan adanya hubungan antara kompetensi sosial dengan prestasi mahasiswa, bahwa seorang tutor memiliki kompetensi sosial tinggi maka kemungkinan prestasi mahasiswa juga meningkat.

\section{Pengaruh kompetensi Pelaksanaan}

Tutorial terhadap prestasi mahasiswa.

Pengujian hipotesis pertama (H5) memiliki nilai $\beta 5=0.049$ dengan tingkat signifikansi sebesar 0,00 I (sig<0,05), sehingga H5 diterima. Jadi variabel pelaksanaan tutorial berpengaruh positif pada prestasi mahasiswa. Penelitian ini bertolk belakang dengan penelitian Widyowati (20l4) yang menjelakan bahwa fasilitas perkuliahan dianggap cukup memadai dan tidak berpengaruh terhadap prestasi mahasiswa.

\section{KESIMPULAN}

Penelitian ini bertujuan untuk mengetahui pengaruh kompetensi pedagogik, kompetensi profesional, kompetensi kepribadian, kompetensi sosial, pelaksanaan tutorial terhadap prestasi mahasiswa. Berdasarkan hasil penelitian ini, maka dapat diambil kesimpulan sebagai berikut :

I. Kompetensi pedagogik, kompetensi profesional, kompetensi kepribadian, kompetensi sosial, pelaksanaan tutorial secara bersama-sama mempengaruhi prestasi mahasiswa.

2. Kompetensi pedagogik, kompetensi profesional, kompetensi kepribadian, kompetensi sosial, pelaksanaan tutorial berpengaruh positif dan signifikan terhadap prestasi mahasiswa. Semakin tinggi kompetensi pedagogik, kompetensi profesional, kompetensi kepribadian, kompetensi sosial, pelaksanaan tutorial maka akan semakin mempengaruhi prestasi mahasiswa. Sehingga jika variabel tersebut tinggi maka kemungkinan prestasi mahasiswa juga meningkat

Evaluasi atas hasil penelitian ini harus mempertimbangkan keterbatasan yang mungkin mempengaruhi hasil penelitian, di antaranya adalah:

I. Sulitnya mengendalikan responden yaitu pengisian kuesioner diakukan bersamasama mahasiswa lainya (diskusi) sehingga hasil akan berisiko menjadikan hasil menjadi bias. Penelitian selanjutnya dapat menggunakan metode lain seperti wawancara langsung kepada mahasiswa atau setidaknya dapat memastikan pihak responden untuk mebendakan persepsi peniliaan tutor.

2. Penelitian ini menggunakan pengukuran kuisioner yang mungkin menimbulkan bias persepsi atas pertanyaan-pertanyaan yang ada dikuesioner, penelitian selanjutnya dapat menggunakan metode eksperimen untuk menghindari bias persepsi

3. Penelitian ini menggunakan instrumen penelitian yang diadopsi dari kuesinoner peraturan perundang-undnagan, kemudian diadaptasi lagi untuk disesuaikan dalam konteks tutorial (tidak wajib dalam pembelajaran), sehingga masih mungkin ditemukan beberapa kelemahan.

Berdasarkan hasil penelitian yang telah dilakukan maka diajukan saran, antara lain:

I. Penelitian mendatang sebaiknya melakukan sebuah penelitian dengan menggunakan metode wawancara langsung untuk mengumpulkan data penelitian agar dapat mengurangi adanya kelemahan terkait internalal validity.

2. Peneliti juga menyarankan untuk penelitian selanjutnya agar memperluas objek penelitian sehingga hasilnya dapat digeneralisasi.

3. Pada penelitian ini, variabel independen yang diteliti berpengaruh terhadap variabel profesionalisme pengawas sebesar $25.40 \%$, berarti bahwa ada pengaruh sebesar $74.60 \%$ dari variabelvariabel lain , berarti bahwa ada pengaruh sebesar $74.60 \%$ diluar model. Penelitian selanjutnya disarankan untuk meneliti pengaruh variabel-variabel lain yang belum termasuk dalam model regresi 
pada penelitian ini dengan menggunakan metode analisis selain metode regresi.

\section{DAFTAR PUSTAKA}

Al-Mutairi, A. (20II). Factors Affecting Business Students' Performance in Arab Open University: The Case of Kuwait. International Journal of Business and Management, 6(5), 146-I55.

Andriani, D. (2005). Mahasiswa S2 pada sistem pendidikan jarak jauh: Pemanfaatan internet dan bantuan belajar. Jurnal Pendidikan Terbuka dan Jarak Jauh, 6(2), 77-9I.

Azwar, S. 2006. Reliabilitas dan Validitas. Yogyakarta: Pustaka Pelajar.

Akiri, A. A., \& Ugborugbo, N. M. (2009). Teachers' Effectiveness and Students' Academic Performance in Public Secondary Schools in Delta State, Nigeria. Studies on Home and Community Science, 3(2), I07-II3. https://doi.org//0.1080/09737/89.200 9.1 1885284

Chamorro-Premuzic, T., Adrian, F \& Martin, L. 2007. Personality and approaches to learning predict preference for different teaching methods. Learning and Individual Differences. Vol. 17, Pp: 24I-250.

Bonney, E. A., Amoah, D. F., Micah, S. A., \& Lemaire, M. B. (20I5). The Relationship between the Quality of Teachers and Pupils Academic Performance in the STMA Junior High Schools of the Western Region of Ghana. Journal of Education and Practice, 6(24), 139-150. Retrieved from https://files.eric.ed.gov/ fulltext/EJ I 0788 I8.pdf

Djamarah, Syaiful Bahri. 1994. Prestasi Belajar dan Kompetensi Guru. Surabaya: Usaha Nasional

Fairclough, M. (2008). Supporting learners in lifelong learning sector. London: Open University Press McGraw-Hill Education.

Frisdiantara, C., \& Graha, A. N. (20/3). Pengaruh Dimensi Pelayanan Dan Dimensi Fasilitas Terhadap

Gunarso, S..D. $1985 . \quad$ Psikologi Perkembangan Anak Dan Remaja, Jakarta, Gunung Mulia.

Hartono, Roni. (2020). EVALUASI PROGRAM PENDIDIKAN KARAKTER BERBASIS REVOLUSI MENTAL SEKOLAH MENENGAH PERTAMA DI KABUPATEN SUMBAWA. Jurnal Evaluasi Pendidikan, II (I), $17 \quad-\quad 24$. Https://Doi.Org/I 0.2 I009/JEP.0I I I.03
Hakim, Adnan. 20I5. Contribution of Competence Teacher (Pedagogical, Personality, Professional Competence and Social) On the Performance of Learning. The International Journal Of Engineering And Science (IJES). Volume 4, Issue 2, Pp .0I-12

Hasibuan, Malayu S.P. 2007. Organisasi dan Motivasi Dasar Peningkatan Produktivitas. Jakarta: Bumi Aksara. Hornby dan Thomas (Prihadi, 2004: 89). Assesment Centre: Identifikasi, Pengukuran dan Pengembangan Kedisiplinan Dosen. Jakarta: PT Gramedia Pustaka Utama.

Hendrayana, Angga S. dkk (20l4). Motivasi Belajar, Kemandirian Belajar Dan Prestasi Belajar Mahasiswa Beasiswa Bidikmisi di UPBJJ UT Bandung. Jurnal Pendidikan Terbuka dan Jarak Jauh, Volume 15, Nomor 2, pp. 81-87

Husnan. 2013. Kompetensi Profesional dan Pengaruhnya Terhadap Kinerja Dosen STAI DDI Maros. Jurnal Al Hikmah, Vol. XIV Nomor $1 / 2013$.

Rabiatul Adawiah. (2020). THE APPLICATION-BASED ANALYSIS OF QUESTIONS ITEM QUALITY IN JUNIOR HIGH SCHOOL. JISAE: Journal of Indonesian Student Assessment and Evaluation, 6(2), I40 - I 48. https://doi.org// 0.21009/JISAE.062.04

llyas (2008). Fungsi dan Pengukuran Prestasi Belajar. Yogyakarta : Pustaka Belajar

Kurniawan, Oce. (2003). Membenahi Pengelolaan Pendidikan Nasional dalam Cakrawala Pendidikan. Jakarta: Universitas Terbuka.

Kosgei, A., Mise, J. K., Odera, O., \& Ayugi, M. E. (20|3). Influence of teacher characteristics on students' academic achievement among secondary schools. Journal of Education and Practice , 4(3), 76-82. Retrieved from https://eprints.usq.edu.au/23286/I/Kos gei.pdfhttps://doi.org//0.5539/ ijbm.v6n5pl46

Lastuti, S., \& Jaedun, A. (20|4). Evaluasi pelaksanaan program SI PGSD di unit program belajar jarak jauh UT DIY. Jurnal Kependidikan: Penelitian Inovasi Pembelajaran, 44(I).

Lucia dan Lepsiger (Prihadi, 2004). Assesment Centre: Identifikasi, Pengukuran dan Pengembangan Kedisiplinan Dosen. Jakarta: PT Gramedia Pustaka Utama.

Mangkunegara, A.A., Anwar Prabu. 2000. Manajemen Sumber Daya Manusia. Bandung: PT Remaja Rosdakarya. 
Mangkunegara, Anwar Prabu, 2000. Kualitas Sumber Daya Manusia Perusahaan. Bandung: UNPAS.

Mediawati, E. (20I0). Pengaruh motivasi belajar mahasiswa dan kompetensi dosen terhadap prestasi belajar. Dinamika Pendidikan, 5(2).

Mulyasa, E. 2007. Standar Kompetensi dan Sertifikasi Guru. Bandung: Re-maja Rosdakarya.

Muzenda, A. (20I3). Lecturers' Competences and Students' Academic Performance. International Journal of Humanities and Social Science Invention ISSN (Online, 23 19-7722.

Novak, J.D. \& Canas, A. (2008). The theory underlying concept maps and how to construct and use them. Technical Report IHMC Cmap Tools 2006-0I Rev 0 I-2008. Diambil pada tanggal 2 April 2020 dari http://cmap.ihmc.us/docs/theory-ofconcept-maps.php.

Ormond, S. (2000). Supporting students in open and distance learning. London: Kogan Page Limited.

Putra, A., Widowati, S., \& Solikin, S. (20I5). Evaluasi Sistem Pembelajaran Jarak Jauh Menggunakan Multi-criteria Methodology (studi Kasus: Pembelajaran Jarak Jauh Telkom University). eProceedings of Engineering, 2(3).

Purwanto, Ngalim. 2006. Psikologi Pendidikan. Bandung: Remaja Rosdakarya

Prayekti, P., \& Nurdin, G. (20II). FaktorFaktor Yang Mempengaruhi Kualitas Tutorial Program SI PGSD Fakultas Keguruan dan Ilmu Pendidikan Universitas Terbuka. Jurnal Pendidikan dan Kebudayaan, I7(3), 316-328.

Rivai, Veithzal and Mohd. Basri, Ahmad Fauzi, Performance Apraisal: Sistem yang tepat untuk menilai kinerja karyawan dan meningkatkan daya saing perusahaan (Jakarta: Raja Grafindo, 2005).
Rossi, P. H. \& Freeman, E. H. 1985. Evaluation Systematic Approach. California: Sage Publications, Inc.

Sastrohadiwiryo, Siswanto. 2002. Manajemen Tenaga Kerja Indonesia.jakarta: Bumi Aksara.

Slameto (2010). Belajar dan Faktor-Faktor yang Mempengaruhinya. Jakarta : PT. Rineka Cipta

Suryanto, A., Gafur, A., \& Sudarsono, F. X. (2013). Model Evaluasi Program Tutorial Tatap Muka Universitas Terbuka. Jurnal Penelitian dan Evaluasi Pendidikan, I7(2), 198-2।4.

Susilowati, EM dan Solikhan, Badingatus, 2014. Profesionalisme Akuntan Pendidik : Perspektif atau Triger Kualitas Lulusan Akuntansi di Era Masyarakat Ekpnomii Asean. Jurnal Akuntansi dan Auditing Vol. I I, No. I : 103-119

Van Schweitzer, H. (2009). Internal audit-the conscience of the organisation. IA Adviser.

Widyowati, Dyah. "Pengaruh kompetensi profesional dosen dan fasilitas perkuliahan terhadap prestasi Mahasiswa Politeknik NSC Surabaya." Jurnal Bisnis Teknologi I.I (20I4): 8-I4.

Widatik, Catur. 2016. "Pengaruh kecerdasan emosional, kecerdasan intelektual, kecerdasan piritual, kecerdasan sosial Terhadap pemahaman Akuntansi”. Jurnal Akuntansi dan Sistem Teknologi nformasi Vol. 12 No. I. hlm: 17 - 26.

Winkel, W.S. (2007). Psikologi Pengajaran. Yogyakarta : Media Abadi

Winkel, W.S. 2009. Psikologi Pendidikan dan Evaluasi Belajar. Jakarta. Gramedia.

Wijaya, Cece dan Rusyan, A. Tabrani. 1994. Kemampuan Dasar Guru Dalam Proses Belajar-Mengajar. Bandung: Remaja Rosdakarya

Undang-undang Nomor 20 Tahun 2003 tentang Sistem Pendidikan Nasional 